\title{
KEBERADAAN PESUT (Orcaella brevirostris) DI SUNGAI MAHAKAM, KALIMANTAN TIMUR*
}

\author{
Dian Oktaviani'), Syahroma H. Nasution'2), dan Dharmadi') \\ 1) Peneliti pada Pusat Riset Perikanan Tangkap, Ancol-Jakarta \\ 2) Peneliti pada Pusat Penelitian Limnologi-Lembaga IImu Pengetahuan Indonesia, Cibinong \\ Teregristrasi I tanggal: 20 Pebruari 2006; Disetujui terbit tanggal: 4 Oktober 2006
}

\begin{abstract}
ABSTRAK
Pesut atau dalam bahasa Inggris dikenal dengan sebutan Irrawaddy dolphin dengan nama ilmiah (Orcaella brevirotris) adalah spesies mamalia air tawar yang dilindungi baik secara nasional maupun internasional. Sungai Mahakam yang berada di Propinsi Kalimantan merupakan salah satu habitat pesut di Indonesia, dan sampai dengan saat ini dapat dilihat keberadaan. Populasi pesut yang semakin turun sehingga memerlukan perhatian dalam upaya mempertahankan keberadaan. Upaya tersebut memerlukan koordinasi yang baik antara pemerintah dan masyarakat dalam menjaga kualitas habitat dan pesut.
\end{abstract}

KATAKUNCI: $\quad$ pesut, Orcaella brevirostris, habitat, Sungai Mahakam, Kalimantan Timur

\section{PENDAHULUAN}

Sungai Mahakam sebagaimana sungai besar lain di Indonesia bersifat multi fungsi. Salah satu fungsi utama dari sungai adalah sebagai sumber penghidupan bagi penduduk di sekitar seperti kebutuhan air dan juga dapat menjadi sumber mata pencarian bagi nelayan. Perkembangan jumlah penduduk di sepanjang Sungai Mahakam berkembang dengan cepat terutama di bagian sungai yang merupakan tepat pemukiman penduduk. Selain itu, Sungai Mahakam dikenal sebagai habitat alami dari berbagai jenis ikan, burung air, dan juga beberapa jenis mamalia air lain. Mamalia air tawar yang sangat dikenal berasal dari sungai ini adalah pesut. Pesut atau dalam bahasa Inggris dikenal dengan sebutan Irrawaddy dolphin dengan nama ilmiah (Orcaella brevirotris) merupakan salah satu jenis yang dilindungi baik secara nasional maupun internasional. Pemerintah telah menetapkan bahwa pesut termasuk hewan dilindungi yang tercantum dalam PP No.7 tahun 199. Di dunia internasional pesut masuk dalam daftar CITES yang digolongkan ke dalam Lampiran 1. Penggolongan ini merupakan hasil pertemuan CoP 13 CITES di Bangkok yang sebelum termasuk dalam Lampiran 2. Pesut merupakan simbol kebanggaan bagi Propinsi Kalimantan Timur, namun sampai dengan saat ini belum ada tindakan secara khusus dalam hal pengelolaan perlindungan.

\section{BIOLOGI PESUT}

Pesut merupakan jenis hewan menyusui dan habitat air tawar (sungai, danau, dan muara sungai), berikut urutan takson dari pesut:

\section{Phyllum: Chordata \\ Class: Mammalia \\ Ordo: Cetacea \\ Family: Delphinidae \\ Genus: Orcaella \\ Spesies: Orcaella brevirotris}

Pesut memiliki warna tubuh abu-abu gelap sampai dengan bau-abu terang (Arnold, 2002 dalam CMS website). Panjang tubuh mencapai $2,5 \mathrm{~m}$ dengan bobot $>100 \mathrm{~kg}$ (Gambar 1). Pesut betina hamil selama 14 bulan dan melahirkan seekor anak.

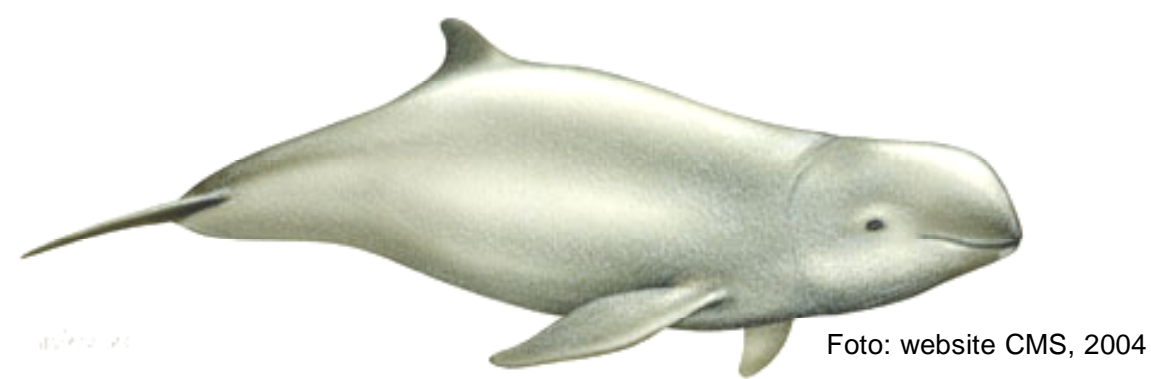

Gambar 1. Pesut (Orcaella brevirostris). 
Makanan utama pesut adalah ikan bersirip lunak yang pada umumnya termasuk dalam kelompok ikan putihan. Selain itu, juga ada informasi yang mengatakan bahwa makanan pesut selain ikan juga udang (Ridgway \& Harrison, 1989). Hasil tangkapan nelayan di Danau Melintang dan Danau Semayang terdapat jenis-jenis ikan putihan seperti repang (Osteochilus repang), tebal dada (Rohteicthys microlepis), pahat (Puntius nini), salap (Puntius schwanefeld $l$ ), dan barukung (Barbichthys laevis). Jenis-jenis ikan putihan tersebut dapat menjadi makanan bagi pesut. Kepastian jenis ikan yang dimakan oleh pesut belum dapat diketahui, sehingga hal ini memerlukan penelitian lebih lanjut.

Pesut pada umumnya hidup berkelompok antara 6 sampai dengan 15 ekor (Marsh et al., 1989). Gambar
2 memperlihatkan sekelompok pesut yang sedang berenang di Sungai Pella menuju ke Sungai Mahakam. Pergerakan pesut disinyalir mengikuti pergerakan ikan. Hal tersebut, dengan mekanisme cara perburuan yang memanfaatkan kemampuan ekolokasi untuk mendeteksi mangsa. Seperti kelompok cetacean lain pesut juga mempunyai kemampuan ekolokasi. Frekuensi dominan yang dipakai tercatat $60 \mathrm{kHz}$ (Kamminga, 1983). Namun, dugaan pergerakan pesut mengikuti pergerakan ikan memerlukan kajian yang lebih dalam dengan bantuan peralatan khusus.

Gambar 2 juga memperlihat bentuk kepala yang bundar, moncong pendek, dan bentuk sirip punggung kecil terletak semi dorsal, yang menurut Carwadine (2002) merupakan ciri khusus bagi Orcaella brevirostris.

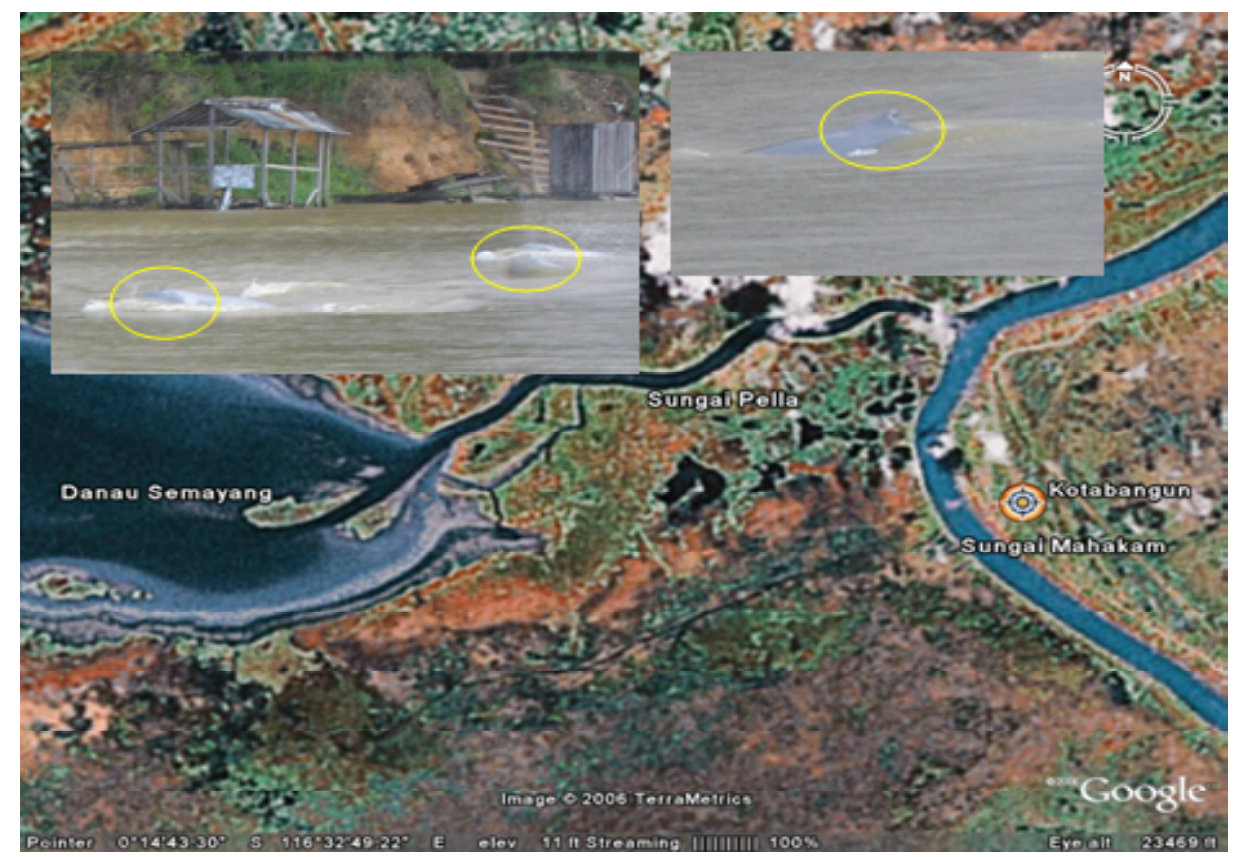

Gambar 2. Kelompok pesut dengan bentuk kepala bundar (kiri); bentuk sirip punggung (kanan) sedang berenang di Sungai Pella.

\section{GAMBARAN KEADAAN HABITAT PESUT DI SUNGAI MAHAKAM}

Setiap waktu jumlah penduduk di suatu tempat akan mengalami perkembangan yang pesat, demikian pula yang terjadi di sepanjang Sungai Mahakam (Gambar 3). Perkembangan penduduk tersebut tentu diikuti dengan bertambah aktivitas penduduk seperti transportasi, pemanfaatan air untuk keperluan rumah tangga, penangkapan ikan, pembukaan Iahan perkebunan dan persawahan, dan tempat penjualan bahan bakar (solar, minyak tanah, dan bensin).
Aktivitas yang dilakukan penduduk di sekitar habitat pesut ini berpengaruh juga terhadap tingkah laku pesut. Salah satu dari alat transportasi yang menggunakan mesin bermotor, di mana pesut akan menghindarkan diri dari perahu bermotor tersebut. Selain itu, aktivitas penangkapan ikan yang dilakukan oleh penduduk dapat juga berpengaruh pada populasi pesut. Hal itu, dapat berakibat pada persaingan dalam mendapatkan ikan dan terjerat pada jaring nelayan. Aktivitas penduduk berada pada alur ruaya pesut seperti yang tergambar pada Gambar 4. Sepanjang alur ruaya pesut tidak terlepas dari aktivitas penduduk, terutama transportasi dan menangkap ikan. 


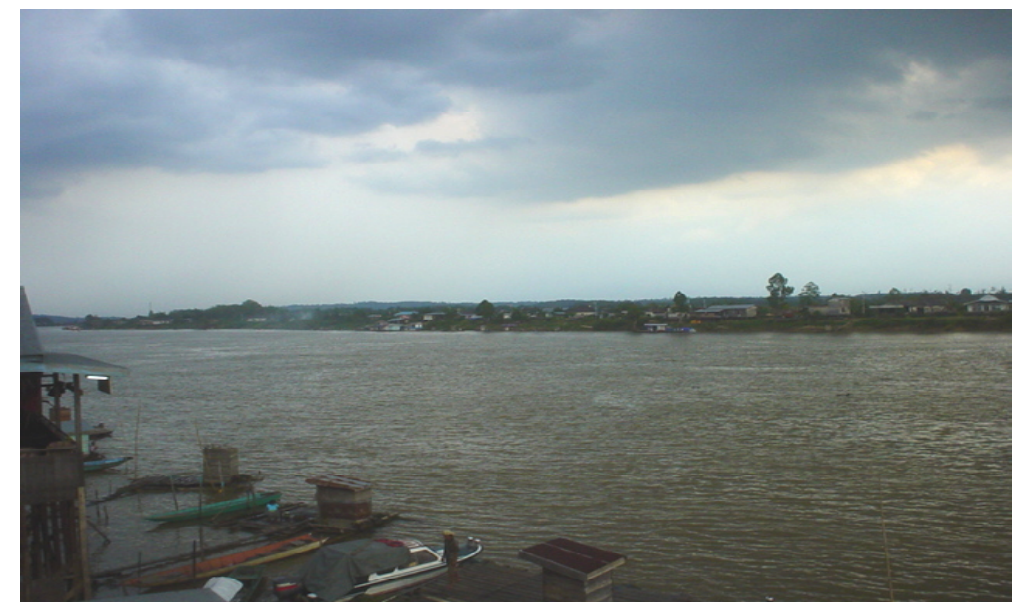

Gambar 3. Perumahan penduduk di sepanjang Sungai Mahakam.

\section{POPULASI PESUT MAHAKAM (Orcaella brevirotris)}

Daerah penyebaran spesies meliputi daerah populasi yang terisolasi secara geografi yaitu Australia, Bangladesh, Cambodia, India, Indonesia, Laos, Malaysia, Myanmar, Papua New Guinea, Philippines, Thailand, Timor Leste, dan Vietnam (Gambar 5) (Kreb, 2004).Di Indonesia pesut dapat ditemukan di daerah aliran Sungai Mahakam Propinsi Kalimantan Timur (Gambar 6), populasi diperkirakan sekitar 34 ekor yang berarti tidak lebih dari 50 ekor (www.panda.org/species/CITES, 2004). Krebs (2004) mengestimasi bahwa jumlah pesut yang ada di daerah aliran Sungai Mahakam adalah 34 ekor. Angka perkiraan populasi ini merupakan gambaran dari indikasi bahwa terjadi penurunan jumlah populasi yang

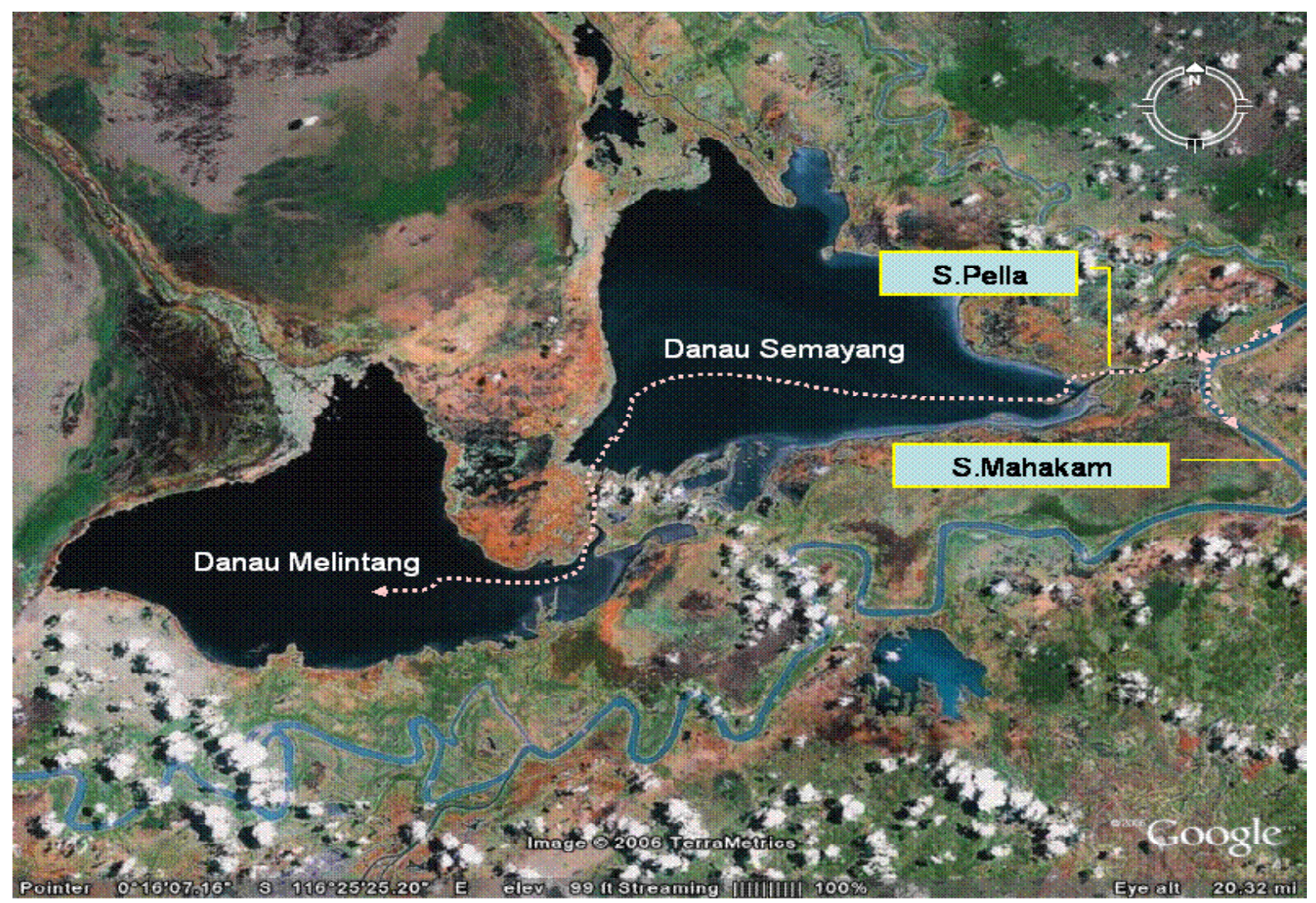

Gambar 4. Alur ruaya pesut pada lahan yang merupakan tempat bermain (playing ground) dan tempat mencari makan (feeding ground) di Sungai Makaham sampai dengan Danau Melintang. 


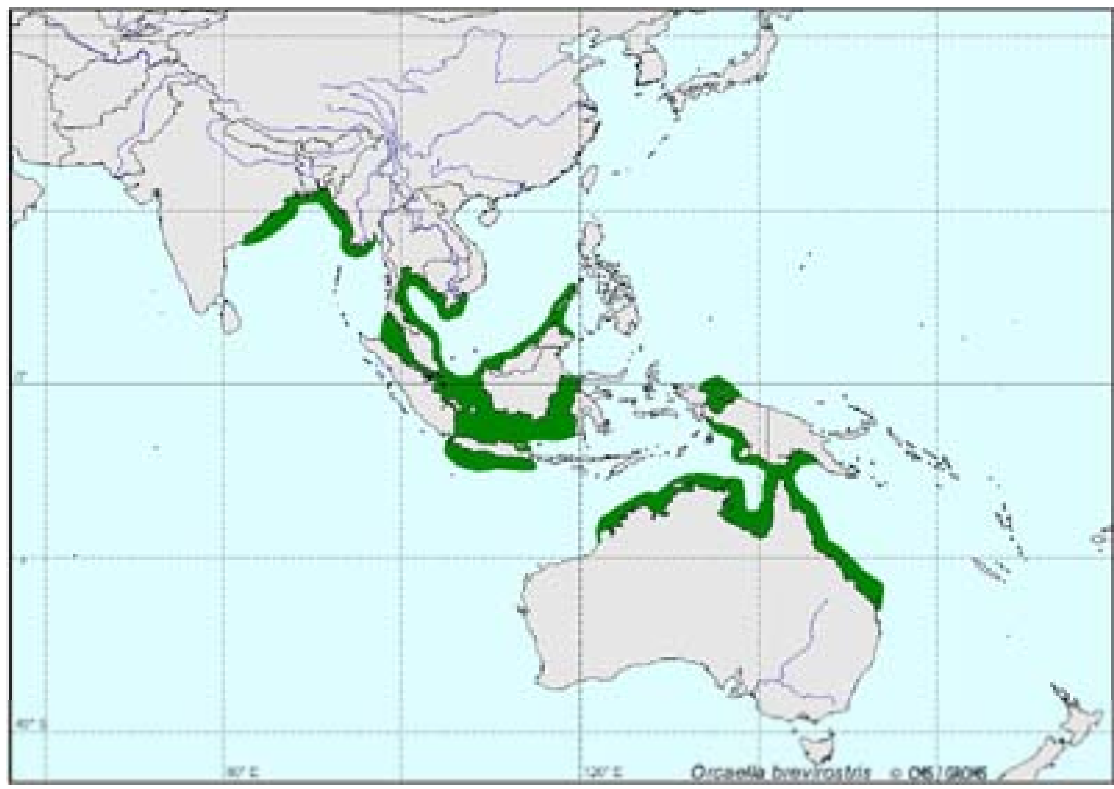

Gambar 5. Distribusi Orcaella brevirostris di dunia.

Sumber: mod. from Arnold, 2002; copyright CMS/GROMS

sekitar tahun 1970-an dikatakan antara 100 sampai dengan 150 ekor yang berlokasi di Danau Melintang, Danau Semayang, Sungai Pela, dan sebagian Sungai Mahakam (Ridgway \& Harrison, 1989; website CMS: Orcaella brevirotris, Irrawady dolphin, 2004). Jadi, dalam jangka waktu sekitar 25 tahun terjadi penurunan jumlah sekitar $30 \%$. Dari keadaan ini, dapat dikatakan bahwa keberadaan spesies Orcaella brevirostris dikhawatirkan akan mengarah pada kepunahan.
Ilustrasi pada Gambar 5 merupakan gambaran di mana kelompok pesut sering terlihat dan dikatakan dalam beberapa literatur.

Kota Bangun merupakan ibu kota kabupaten yang posisi dekat habitat pesut, sehingga aktivitas penduduk sangat berpengaruh terhadap habitat dan populasi pesut (Gambar 4). Kekhawatiran ini tergambar dengan naik status pesut dalam daftar CITES dari Lampiran 2 menjadi Lampiran 1 dan juga

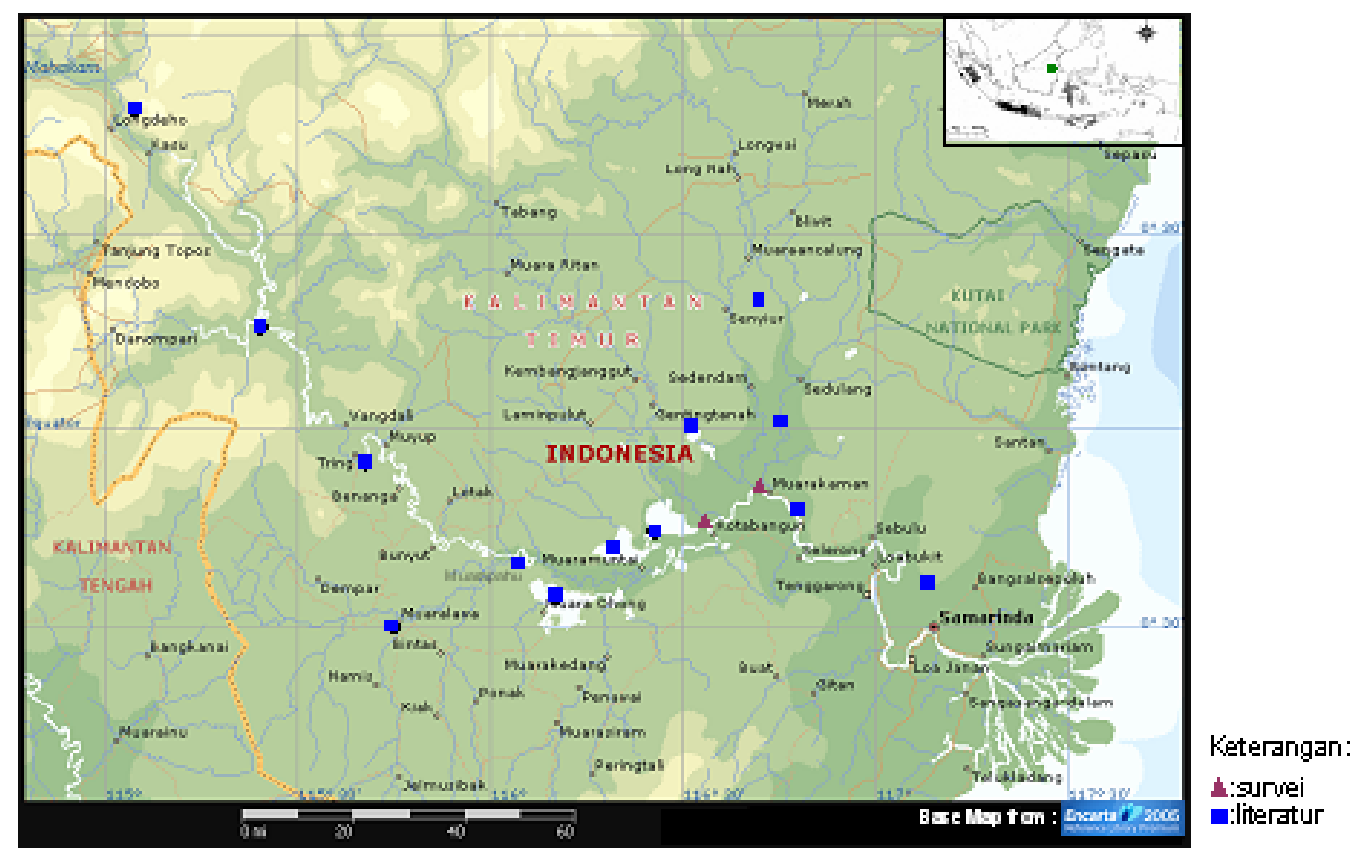

Gambar 6. Lokasi pesut di Kalimantan Timur. Sumber: Priyono (1993); Krebs (2004) 
status di dalam Redlist IUCN tergolong dalam critically endangered dengan status tambahan data deficient. Status sebagai data deficient berarti bahwa belum banyak diketahui tentang spesies ini. Apabila hal ini dibiarkan kekhawatiran akan punah ini bahwa spesies ini dapat terjadi dalam jangka waktu yang sangat cepat.

\section{ANCAMAN DAN PELUANG BAGI}

Perkembangan dan aktivitas penduduk di sekitar habitat pesut dapat menjadi ancaman bagi populasi pesut di Sungai Mahakam. Beberapa ancaman tersebut adalah sebagai berikut:

1. Degradasi habitat (habitat degradation).

2. Terjebak dalam jaring nelayan (incedental catch).

3. Penangkapan ikan yang berlebihan (overfishing).

4. Polusi.

Dari ancaman-ancaman terhadap populasi pesut tersebut terdapat juga beberapa peluang untuk melindungi populasi pesut yang ada. Peluang tersebut adalah:

1. Perbaikan habitat.

2. Pengelolaan suaka perikanan.

3. Tidak ada penangkapan oleh penduduk sekitar habitat.

Peluang pengelolaan suaka perikanan terkait dengan ketersedian stok makanan berupa ikan yang menjadi makanan utama bagi pesut. Peluang lain yang sangat mendukung bagi perlindungan pesut di Sungai Mahakam yaitu tidak ada penangkapan pesut oleh penduduk sekitar. Jadi, dapat dikatakan bahwa penduduk di sekitar habitat pesut tidak pernah memanfaatkan pesut menjadi obyek penangkapan. Hanya terkadang pesut terperangkap di jaring yang dipasang oleh nelayan yang menjadi tempat bermain dan mencari makan bagi pesut.

Kendala bagi pengelolaan pesut saat ini adalah belum ada koordinasi yang pasti dan perhatian yang khusus untuk menangani pengelolaan habitat pesut.

\section{STRATEGI PENGELOLAAN PERLINDUNGAN PESUT MAHAKAM}

Pesut termasuk dalam satwa liar yang mempunyai peran bagi kehidupan manusia. Nilai-nilai pada satwa liar meliputi nilai ekonomis, nilai rekreasi, nilai keindahan dan estetika, dan nilai ilmu pengetahuan (Alikodra, 2002). Berdasarkan pada nilai-nilai tersebut, maka stategi pengelolaan perlindungan terhadap satwa liar terutama untuk spesies yang terancam punah perlu segera mendapatkan perhatian.

Keberadaan pesut di dunia semakin hari semakin menurun. Populasi pesut sangat dipengaruhi oleh degradasi kualitas lingkungan perairan yang terkait dengan pasokan sumber makanan. Salah satu strategi atau action plan untuk melindungi populasi pesut seperti diagram pada Gambar 7 .

Diagram pada Gambar 7 mencoba untuk menggambarkan strategi perlindungan yang terkait dengan biologi dari pesut, yaitu salah satunya adalah bahwa $80 \%$ dari seluruh hidup adalah aktivitas mencari makan. Adapun makanan utama bagi pesut adalah ikan, sehingga strategi yang mungkin dilakukan adalah dengan memperbaiki tempat-tempat yang menjadi

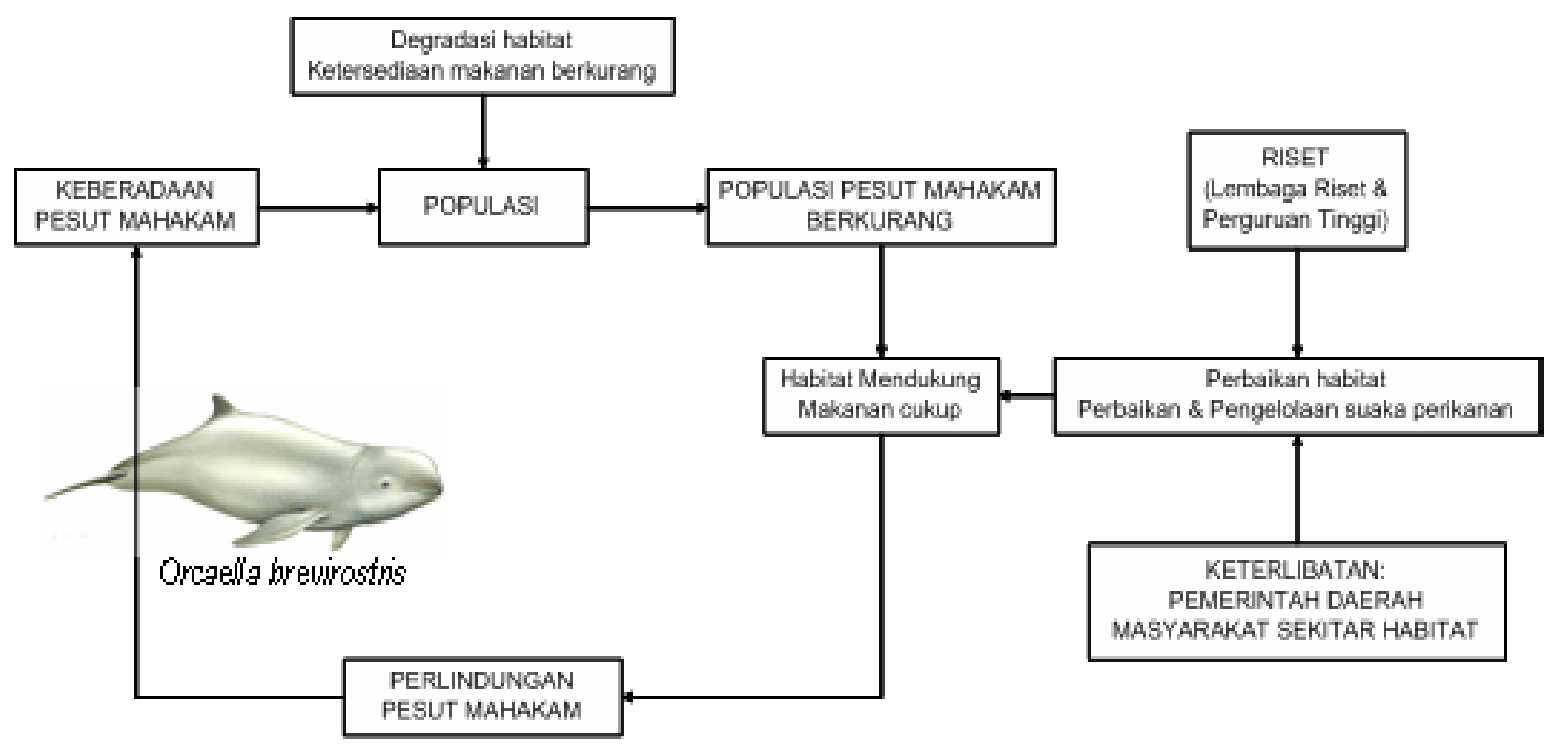

Gambar 7. Diagram alur strategi perlindungan pesut (Orcella brevirostris). 
sumber makanan. Selain itu, diagram ini menggambarkan juga pihak-pihak yang terkait dalam usaha pengelolaan perlindungan pesut. Jadi, pengelolaan perlindungan bagi spesies ini tidak hanya menjadi tanggung jawab instansi tertentu ataupun hanya pemerintah, namun merupakan tanggung jawab semua pihak yaitu instansi pemerintah (pusat dan daerah) dan masyarakat.

\section{KESIMPULAN}

Kesimpulan yang didapat adalah sebagai berikut:

1. Populasi pesut di Sungai Mahakam mengalami penurunan dan terancam punah.

2. Kerja sama yang baik antara pemerintah dan masyarakat sangat diperlukan dalam pengelolaan perlindungan pesut, terutama pihak-pihak yang berada langsung di sekitar habitat pesut.

3. Penanganan dan strategi pengelolaan yang tepat harus segera dilakukan.

4. Dampak lain dari strategi pengelolaan yang berdasarkan pada pengendalian degradasi habitat dapat berpengaruh pada populasi spesies ikan yang ada di habitat pesut.

5. Perlu penelitian yang lebih mendalam mengenai biologi pesut di Sungai Mahakam, antara lain meliputi distribusi, bioekologi, perilaku, dan reproduksi, sehingga didapatkan informasi dasar bagi strategi pengelolaan perlindungan.

\section{Persantunan: \\ Hasil dari kegiatan riset: Inventarisasi Mamalia Air T.A. 2004-2005 di Pusat Riset Perikanan Tangkap}

\section{DAFTAR PUSTAKA}

Alikodra, H. S. 2002. Pengelolaan satwa liar. Jilid 1. Yayasan Penerbit Fakultas Kehutanan Institut Pertanian Bogor. Bogor. pp: 24-29.
Arnold ,P. W. 2002. Irrawady dolphin-Orcaella brevirotris. In: Encyclopedia of marine mammals (Perrin WF, Wûrsig B, Thewissen JGM, eds) Academic Press. Sandiego. 652-654.

Carwadine, M. 2002. Handbooks: Whales, dolphin, and porpois. Dorling Kindersley Publishing. Inc. New York. pp: 222-223.

Kamminga. 1983. In: Ridgway, S. H. \& S. R. Harisson. 1989. Handbook of marine mammals. Vol.4: River dolphins and the larger toothed Whales. Academic Press Limited. Toronto: 113.

Marsh H., Lloze R., Heinsohn G. E., \& Kasuya T. 1989. Irrawady dolphin-Orcaella brevirotris (Gray, 1866) In: Handbook of Marine Mammals (Ridgway S. H., Harisson S. R. eds.) Vol.4: River Dolphin and the Larger Toothed Whales. Academic Pres. London. pp. 101-118.

Priyono. 1993. Telaah habitat pesut (Orcaella brevirotris) di Danau Semayang dan sekitarnya. Dalam: Suharso, A. 1995. Studi habiatat dan penyebaran pesut (Orcaella brevirotris) di Muara Sungai Citanduy dan perairan Segara Anakan. Skripsi. Jurusan Konservasi Sumber Daya Hutan. Fakultas Kehutanan. Institut Pertanian Bogor. Bogor. 9.

Kreb, D. 2004. Facultative river dolphins: Conservation and social ecology of freshwater and coastal irrawaddy dolphin in Indonesia. Febodruk B. V. Enschede: 1-230; i-iv.

Ridgway, S. H. \& S. R. Harisson. 1989. Handbook of Marine Mammals. Vol.4: River dolphins and the larger toothed Whales. Academic Press Limited. Toronto.

Website CMS. 2004.

Website CITES. 2005. 